\title{
Research on the Effectiveness of Nutrition and Food Safety Education of the Taekwondo College Students in China Based on Local Fractional Algorithm
}

\author{
Guo-qing Su*
}

Department of Physical Education, Xi'an University of Posts and Telecommunications, Xi'an, P.R. China

\begin{abstract}
In order to evaluate the current effectiveness of nutrition and food safety education on the Taekwondo college students in China, this study analysed the difference of food knowledge, attitudes and practices among the Chinese taekwondo college students on the basis of local fraction algorithm to examine who had or had not received food nutrition and safety education, in order to examine the necessarily of the provision of food nutrition and safety education in the college. Two groups of students were formed with 150 samples in one group respectively. One group of students, named FNSE group, had received food nutrition and safety education, while the other, named non-FNSE group, did not. The differences in the knowledge, attitudes and practices regarding food of two groups of student were compared using the data collected by questionnaires. The results revealed that students in FNSE group had greater knowledge than students in the other one with a significant difference $(\mathrm{P}=0.013<0.05)$. Regarding food attitude, food nutrition and safety education did not cause any difference between the two groups. FNSE group performed better than the non-FNSE group on the nutritional and dietary practice. Since food nutrition and safety education can improve taekwondo college students' food knowledge and influence their dietary behavior, this study empirically supports the implementation of food nutrition and safety education in colleges, and suggests that the education should be tailored for taekwondo college students.
\end{abstract}

Keywords: Nutrition and food safety education, FNSE, Taekwondo college students, Local fractional algorithm, Effectiveness education.

\section{INTRODUCTION}

Taekwondo is a Korean martial art. It combines combat and self-defense techniques with sport and exercise. It is also a type of sparring, which has been an Olympic event since 2000. Taekwondo was developed by a variety of Korean masters during the 1940s and 50s; the most well-known being General Choi Hong $\mathrm{Hi}$, as a combination of Okinawan karate, Chinese martial arts, and the ancient Korean traditions skills [1].

In 1973, the South Korean government's Ministry of Culture, Sports and Tourism established the Kukkiwon as the new national academy for taekwondo. Kukkiwon now serves many of the functions previously served by the KTA, in terms of defining a government-sponsored unified style of taekwondo. In 1973, the KTA established the World Taekwondo Federation (WTF) to promote taekwondo specifically as a sport. WTF competitions employ Kukkiwon-style taekwondo. For this reason, Kukkiwon-style taekwondo is often referred to as WTF-style taekwondo, sport-style taekwondo, or Olympic-style taekwondo, though in reality the style is defined by the Kukkiwon, not the WTF [2].

Since 2000, taekwondo has been one of only two Asian martial arts (the other being judo) that are included in the

\footnotetext{
*Address correspondence to this author at the Department of Physical Education, Xi'an University of Posts and Telecommunications, Xi'an, P.R. China; Tel: +358-6-3247476; Fax: +358-6-3247457; E-mail: hunter2011@foxmail.com
}

Olympic Games. It became a demonstration event at the 1988 games in Seoul, and became an official medal event in 2000 games in Sydney. In 2010, taekwondo was accepted as a Commonwealth Games sport.

Taekwondo as a confrontational sport, has great demand for physical health for athletes. In the confrontation of taekwondo, physical deficiencies will seriously affect the athlete's ability to execute technically and tactically seriously. Especially after the change in taekwondo competition rules, taekwondo has proposed higher requirements for physical health to athletes, for daily training, and core strength training is employed when coaches train taekwondo athletes [3].

In the past ten years, local fractional calculus has been widely applied to many fields such as mathematics, image processing, signal processing, etc. Some authors have given many definitions of local fractional derivatives and local fractional integrals (also called fractal calculus). Hereby this paper restates $r$ the following local fractional derivative which is given by Yan.

Healthy dietary behavior has positive effect on the physical and metal developments of college taekwondo students. The previous research focusing on Chinese college taekwondo students' dietary behavior revealed that there were many taekwondo college students having unhealthy dietary habits or practices. Some of them experienced malnutrition due to their picky eating habits and unbalanced in- 
takes of nutrition. For example, an investigation showed that only $30.33 \%$ of Chinese Taekwondo college students had breakfasts every morning and they preferred to take partake food with limited protein and vitamin for breakfast. For more than $87 \%$ Chinese college taekwondo students, the selections of food were purely based on personal preferences without nutritional and safety consideration. Only $38.38 \%$ of Taekwondo college students used to have appropriate amount of meat, eggs and beans daily. Besides unhealthy eating behavior, food safety issues also occurred among the Taekwondo college students [4].

Previous studies revealed unsatisfactory knowledge of dietary behavior and food among Chinese Taekwondo college students, and proposed the application of food safety and nutrition education with the assumption that education can improve their dietary behaviors. However, the assumption has not been fully supported by previous research. This paper investigated the difference of food nutrition and safety knowledge, attitude and practice among Chinese Taekwondo college students who received or the ones who did not receive food nutrition and safety education. The findings of this study can give an insight about decision making for the implementation of food nutrition and safety education at Chinese colleges [5].

\section{THE CURRENT SITUATION OF NUTRITION AND FOOD SAFETY EDUCATION ON COLLEGE TAEKWONDO STUDENTS IN CHINA}

China has progressed from the surviving stage to the developing stage. In the developing stage, the demand for life quality has increased, since more people are participating in sports, thus new challenges have appear in the development of sports nutrition industry.

First, the market demand of China's sports nutrition industry is insufficient, while the income level and the structure of consumption change, the number of people who actively participate in sports have not increased. People who participate in sports have vague knowledge and recognition of the functions of sports nutrition and the supervision and regulation of food safety are not strict enough. Secondly, the number of suppliers of sports nutrition in the market and the size of sports nutrition market are relatively small. Compared with developed countries, the categories, the number and the quality of sports nutrition still need to be increased. Third, from the perspective of market concentration rate, due to barriers to entry and products differentiation, the current market structure of China's sports nutrition industry is in oligopoly. However, accompanied by the increased number of competitors in the market and the expansion of the market size, the market structure will shift to monopolistic competition. Fourth, the experiences of western countries in the research of sports nutrition, successful marketing strategy and strict governmental supervision and regulation will provide important reference in the development of China's sports nutrition industry.

Based on these few researches, this study proposed the strategy and suggestions for the development of China's sports nutrition industry as follows. The first is the implementation of strategic restructuring. The development of China's sports nutrition starts from elite sport, the overall positioning of China's sports nutrition industry emphasizes on niche markets. With the development of the economy, the market demand is shifting from niche market to mass market. China's sports nutrition industry should make strategic adjustment and facilitate industry development by changing market positioning from elite athletes to mass consumers. Secondly, the research and development of technology should be enhanced. Based on different needs of different groups, China's sports nutrition industry should enhance the functions of sports nutrition by long-term continuous investment; build wholesome service system of sports nutrition in improving health; develop and import the technologies and equipment of food quality supervision and regulation. Third, the companies in sports nutrition industry should emphasize more on promoting new concepts and technologies of sports nutrition, letting more consumers accept the current value of sports nutrition. Fourth, the government should make system reform to ensure orderly competition and healthy development of sports nutrition industry by supervision and regulations. For example, it should build sports nutrition company credit alarming system and risk evaluation system, regularly publicize the list of qualified sports nutrition products and companies, and continuously modify the national standards of sports nutrition. Fifth, the association of sports nutrition should play a significant role in the industry's development by effective communication with government departments. The association should promote the development of sports nutrition supervision, regulation and examination system and national public nutrition examination and evaluation system, modify and improve the association standards of sports nutrition, implement scientific and effective manufacture regulation of sports nutrition, facilitate the introduction of sports nutrition to the public and ensure the rights and benefits of consumers.

In terms of the classification of sports nutrition, it can be classified according to the function and the main components of sports nutrition, both means shall be used alone. Therefore, in this paper, the classification of sports nutrition is combined with the function of sports nutrition and ingredients, in order to cover the entire sports nutrition to provide comprehensive analysis basis [6].

Market demand is the foundation of enterprise survival and development. The modification of sports nutrition food industry also needs the market demand as the basis, and ultimately a well-designed consumption structure and consumption. Sports nutrition demand refers to the public demand for sports nutrition. Sports nutrition demand considers purchase desire as premise which is restricted by the ability to pay. Sports nutrition requirements can be divided into potential demand and effective demand. Potential demand is people's objective demand for sports nutrition food, including the purchase desire, but affected by the affordability and other factors thus are temporarily suppressed, and the demand without purchase desire. The effective demand of sports nutrition refers to the current purchase desire, affordability and current demand that can be reflected through the actual purchasing behavior. The potential demand of sports nutrition is the precondition of effective demand, but the potential demand must be transformed into effective demand, and ultimately lead to sports nutrition consumption, 
which is the basic requirement of sports nutrition food industry development [7].

According to what has been issued like the sports nutrition industry standards and national standards and the development of sports nutrition food industry formats, sports nutrition can be divided into energy supplement, protein supplement, and energy control $[8,9]$.

\section{THE LOCAL FRACTIONAL ALGORITHM AND RESEARCH EXPERIMENT}

The local fractional algorithm can be expressed as following:

$$
\begin{array}{r}
f^{(\alpha)}(x 0)=\left.\frac{d f(x)}{d x^{\alpha}}\right|_{x=x_{0}} \\
=\lim _{\delta x \rightarrow 0} \frac{\Delta^{\alpha}\left(f(x)-f\left(x_{0}\right)\right)}{\left(x-x_{0}\right)^{\alpha}}
\end{array}
$$

for $0<a \leq 1$ where

$$
\begin{aligned}
& \Delta^{\alpha}\left(f(x)-f\left(x_{0}\right)\right) \cong \\
& \Gamma(1+\alpha) \lim _{x \rightarrow \infty} \Delta\left(f(x)-f\left(x_{0}\right)\right)
\end{aligned}
$$

And local fractional integral of $f(x)$ defined by Eq.3.

$$
\begin{aligned}
& { }_{a} I_{b}^{(\alpha)} f(t)=\frac{1}{\Gamma(1+\alpha)} \int_{a}^{b} f(t)(d t)^{\alpha} \\
& =\frac{1}{\Gamma(1+\alpha)} \lim _{\Delta t \rightarrow 0} \sum_{j=0}^{j=N-1} f\left(t_{\mathrm{j}}\right)\left(\Delta t_{\mathrm{j}}\right)^{\alpha}
\end{aligned}
$$

With $\Delta t_{j}=t_{j+1}-t_{j}$ and

$$
\Delta t=\max \left\{\Delta t_{1}, \Delta t_{2}, \cdots, \Delta t_{j}, \cdots\right\}
$$

Where for $j=1,2, \cdots, N-1,\left[t_{j}, t_{j+1}\right]$ is a partition of the interval $[a, b]$ and $t_{0}=a, t_{N}=b$.

If $f(x)$ is defined on the real line $-\infty<x<\infty$, its local fractional Hilbert transform, denoted by $f_{x}^{H, \alpha}(x)$ is defined by

$$
\begin{aligned}
& H_{\alpha}\{f(t)\}=f_{H}^{\alpha}(x) \\
& =\frac{1}{\Gamma(1+\alpha)} \oint_{R} \frac{f(t)}{(t-x)^{\alpha}}(d t)^{\alpha}
\end{aligned}
$$

Where $x$ is real and the integral is treated as a Canchy principal value, that is,

$$
\begin{aligned}
& \frac{1}{\Gamma(1+\alpha)} \oint_{R} \frac{f(t)}{(t-x)^{\alpha}}(d t)^{\alpha} \\
& =\lim _{\varepsilon \rightarrow 0}\left[\frac{1}{\Gamma(1+\alpha)} \int_{-\infty}^{x-\varepsilon} \frac{f(t)}{(t-x)^{\alpha}}(d t)^{\alpha}+\right. \\
& \left.\frac{1}{\Gamma(1+\alpha)} \int_{x+\varepsilon}^{\infty} \frac{f(t)}{(t-x)^{\alpha}}(d t)^{\alpha}\right]
\end{aligned}
$$

To obtain the inverse local fractional Hilbert transform, writing again Eq. (4) as

$$
\begin{aligned}
& f_{H}^{\alpha}(x)=\frac{1}{\Gamma(1+\alpha)} \int_{-\infty}^{\infty} \frac{f(t)}{(t-x)^{\alpha}}(d t)^{\alpha} \\
& =\frac{1}{\Gamma(1+\alpha)} \int_{-\infty}^{\infty} f(t) g(x-t)(d t)^{\alpha} \\
& =f(x) * g(x),
\end{aligned}
$$

The survey was conducted at Binjiang University District, Hangzhou, where 5 universities are located. Three major universities were namely, medicine, nursing and food science and engineering, offering the food nutrition and safety subject for students. 150 taekwondo college students from these three major universities were interviewed with 50 samples for each major university and formed a group named FNSE group. 150 students, of the non-FNSE group, were randomly selected from other major universities. The amount of samples in the non-FNSE group was determined based on the consideration of the balance of sample populations between two groups.

The questionnaire was designed and modified based on the study of Ozilgen published on 2010, which consisted of three parts (i.e. food knowledge, food attitude and dietary practice). The food knowledge was assessed by 12 questions.

The responses to each question were limited to two choices as "having knowledge" and "no knowledge". Regarding the food attitude, the importance of purchase criteria of food, the main risks associated with food and the main trusted sources of information about food risks were evaluated by Likert 5 points scale. The dietary practice part required interviewees to answer the questions, such as the frequencies of having breakfast, the diversity of food and the intake of the unhealthy food, based on their daily eating practice.

The time of survey was from April to June, 2012. The taekwondo college students were approached by two methods. The students in the non-FNSE group were selected by answering the question "did you have food nutrition and safety education before?" The students with a negative answer were interviewed and asked to fulfil the questionnaires at student canteens or other public areas in the universities.

The interviews of students in the FNSE group were conducted during the class breaks in the classrooms. Finally, the non-FNSE group had 123 valid questionnaires, and the number for FNSE group was 125. The data collected from questionnaires was given as input into the computer, and analyzed using the SPSS 18.0. The statistical analysis methods included frequency analysis, $\mathrm{F}$ test and paired samples $\mathrm{T}$ test followed by the analysis.

To assess the gaps/needs related to Nutrition, Physical Activity and Wellness (NPAW) knowledge, skills and training of health professional students, an environmental scan was conducted using multiple methods. Students and faculty members in ten health professional programs were targeted at the University of Alberta: Nutrition, Medicine, Dentistry, Dental Hygiene, Nursing, Pharmacy, Kinesiology, Occupational Therapy, Physical Therapy and Speech Language Pathology. In addition, nutritional services and public health 
staff employed Alberta Health Services (AHS) were included in the study.

Data was gathered through interviews and online surveys with students, faculty members and relevant AHS staff who voluntarily participated. The interviews were semi-structured with open-ended questions focusing on the role of health professionals regarding NPAW, current level and adequacy of NPAW content in curricula including objective-based learning, potential strategies to address gaps in NPAW knowledge and skills, and perceptions on if NPAW should be a part of the curricula within health professional programs and what will be its future. Transcribed interviews were coded to conduct the thematic analysis conducted.

Surveys for all three groups included questions on attitudes/beliefs about NPAW and behavior modification. More specifically, the student survey had 12 questions, some of which focused on program-specific aspects (e.g. time spent on NPAW topics), students' confidence that their programs would adequately prepare them to address NPAW and behavior modification issues with patients/clients, and their interest in receiving additional instruction on NPAW topics. The faculty survey consisted of fifteen questions, some of which focused on their involvement in teaching and/or research concerning NPAW, the challenges and barriers to interdisciplinary teaching and research concerning NPAW. The survey with health professionals within Alberta Health Services included 12 questions, some focused on the professional's demographic information. Most of the questions centered on the common or most frequently asked NPAW questions by patients/clients, their confidence in addressing issues that professionals were deficient in NPAW knowledge and counselling skills, their major sources of NPAW knowledge, and other relevant work- related questions. Survey data of each of the three groups and across the groups were analyzed using basic descriptive frequencies and the cross-tabulations.

\section{THE RESULT AND ANALYSIS}

As shown in Table 1, the FNSE group performs better on certain questions. Over $70 \%$ of the "FNSE" students stated that eating cooked food, kept at room temperature for $2 \mathrm{~h}$, may cause food poisoning while only small percent of "nonFNSE" students gave the right answer to this question (36.6\%). Around $90 \%$ of the "FNSE" students hadthe knowledge that "most microorganisms grow well between 5 and $65^{\circ} \mathrm{C}$ " and "drinking raw milk is likely to cause food poisoning". The rate of "non-FNSE" students who had such knowledge points was lower $(60-75 \%)$. The mean percentages of right answers for the first 5 questions for two groups were $80.7 \%$ (FNSE group) and $58.9 \%$ (non-FNSE group). The $\mathrm{P}$ values of $\mathrm{F}$ test and $\mathrm{T}$ test were equal to 0.282 and $0.013(<0.05)$ respectively which indicated significant difference between the two groups.

Two groups did not show any difference on the last 7 questions (See the Table l). The mean percentage of the awareness of these knowledge points for the FNSE group was $61.8 \%$, and for the non-FNSE group was $60.8 \%$. The $p$ values of $F$ test and $T$ test were 0.38 and $0.445(>0.05)$ respectively which indicate that both groups performed average on obtaining these food safety knowledge points.
Table 1. The difference of food nutrition and safety knowledge between the two groups.

\begin{tabular}{|c|c|c|c|}
\hline \multirow{2}{*}{\multicolumn{2}{|c|}{ Food nutrition and safety knowledge }} & \multicolumn{2}{|c|}{$\begin{array}{c}\text { Awareness } \\
\text { percentage } \%\end{array}$} \\
\hline & & \multirow{2}{*}{$\frac{\text { FNSE }}{79.2}$} & \multirow{2}{*}{$\frac{\text { Non-FNSE }}{67.4}$} \\
\hline 1 & $\begin{array}{l}\text { Pathogenic microorganisms cause } \\
\text { food poisoning }\end{array}$ & & \\
\hline 2 & $\begin{array}{l}\text { People are the main source of } \\
\text { food poisoning }\end{array}$ & 70.4 & 53.7 \\
\hline 3 & $\begin{array}{l}\text { Eating cooked food, kept at room } \\
\text { temperature for } 2 \mathrm{~h}, \text { may cause }\end{array}$ & 70.5 & 36.6 \\
\hline 4 & $\begin{array}{l}\text { Drinking raw milk is highly risky } \\
\text { for food poisoning }\end{array}$ & 89.6 & 62.6 \\
\hline 5 & $\begin{array}{l}\text { Most microorganisms grow well } \\
\text { between } 5 \text { and } 65{ }^{\circ} \mathrm{C}\end{array}$ & 93.6 & 74.0 \\
\hline 6 & $\begin{array}{l}\text { Dark vegetables have more } \\
\text { carotene, vitamin B2 and }\end{array}$ & 20.8 & 22.0 \\
\hline 7 & $\begin{array}{l}\text { Refrigeration temperature slows } \\
\text { down the microbial growth }\end{array}$ & 93.6 & 87.0 \\
\hline 8 & $\begin{array}{l}\text { Pasteurization and sterilization are } \\
\text { not the same things }\end{array}$ & 89.6 & 81.3 \\
\hline 9 & $\begin{array}{l}\text { Drinking raw eggs is highly risky } \\
\text { for food poisoning }\end{array}$ & 48.8 & 57.0 \\
\hline 10 & $\begin{array}{l}\text { Eating raw or half-cooked meat is } \\
\text { highly risky for food poisoning }\end{array}$ & 53.6 & 47.2 \\
\hline 11 & $\begin{array}{l}\text { Eating raw unwashed vegetables } \\
\text { is highly risky for food poisoning }\end{array}$ & 69.6 & 70.0 \\
\hline 12 & $\begin{array}{l}\text { Eating unwashed fruit s is highly } \\
\text { risky for food poisoning }\end{array}$ & 56.8 & 56.0 \\
\hline
\end{tabular}

Table 2 shows the important criteria for food purchase. The importance of criteria was almost ranked in the same order across the two groups, except for two factors of "habit" and "price". The FNSE group considered that the habit

Table 2. The difference of food nutrition and safety attitude between the two groups.

\begin{tabular}{|c|c|c|c|c|c|}
\hline $\begin{array}{l}\text { Purchase } \\
\text { criteria }\end{array}$ & FNSE & $\begin{array}{l}\text { Non- } \\
\text { FNSE }\end{array}$ & Main risks & FNSE & $\begin{array}{l}\text { Non- } \\
\text { FNSE }\end{array}$ \\
\hline Quality & 4.08 & 4.06 & $\begin{array}{l}\text { Food } \\
\text { poisoning }\end{array}$ & 4.28 & 4.57 \\
\hline Health & 3.27 & 3.42 & $\begin{array}{l}\text { Toxic } \\
\text { chemicals }\end{array}$ & 4.54 & 4.35 \\
\hline Freshness & 3.04 & 3.01 & $\begin{array}{l}\text { Hygiene at } \\
\text { the place }\end{array}$ & 3.89 & 3.71 \\
\hline Price & 2.65 & 2.84 & $\begin{array}{l}\text { Expiration } \\
\text { date }\end{array}$ & 2.67 & 2.41 \\
\hline Habits & 2.74 & 2.48 & $\begin{array}{l}\text { Allergic } \\
\text { reactions }\end{array}$ & 2.08 & 1.93 \\
\hline Organic & 2.38 & 2.19 & Obesity & 1.84 & 1.88 \\
\hline Brand & 1.54 & 1.45 & $\begin{array}{l}\text { Digestion } \\
\text { problem }\end{array}$ & 1.82 & 1.84 \\
\hline $\begin{array}{l}\text { Family } \\
\text { choices }\end{array}$ & 1.53 & 1.44 & & & \\
\hline $\begin{array}{l}\text { Place of } \\
\text { production }\end{array}$ & 1.23 & 1.43 & & & \\
\hline \multicolumn{2}{|c|}{$\begin{array}{l}\text { Trusted sources of } \\
\text { information }\end{array}$} & \multicolumn{2}{|c|}{ FNSE } & \multicolumn{2}{|c|}{ Non- FNSE } \\
\hline \multicolumn{2}{|c|}{ Doctors } & \multicolumn{2}{|l|}{4.79} & \multicolumn{2}{|l|}{4.33} \\
\hline \multicolumn{2}{|c|}{ Food consumer groups } & \multicolumn{2}{|l|}{4.45} & \multicolumn{2}{|l|}{4.18} \\
\hline \multicolumn{2}{|c|}{ Scientists } & \multicolumn{2}{|l|}{3.76} & \multicolumn{2}{|l|}{3.49} \\
\hline \multicolumn{2}{|c|}{ Family members } & \multicolumn{2}{|l|}{2.66} & \multicolumn{2}{|l|}{2.78} \\
\hline \multicolumn{2}{|c|}{ Government } & \multicolumn{2}{|l|}{1.89} & \multicolumn{2}{|l|}{2.37} \\
\hline \multicolumn{2}{|c|}{ Media } & \multicolumn{2}{|l|}{1.89} & \multicolumn{2}{|l|}{1.90} \\
\hline \multicolumn{2}{|c|}{ Food producers } & \multicolumn{2}{|l|}{1.57} & \multicolumn{2}{|l|}{1.62} \\
\hline
\end{tabular}


of eating is more important than the price of food in terms of the influence of food choice. Groups regarded the quality of food, health and freshness as the most important factors and organic, brand, family choice and place of production as less important factors. The $\mathrm{P}$ value of paired sample $\mathrm{T}$ test was equal to 2.12 which is greater than 0.05 , therefore two groups showed similarity on the importance of purchase criteria of food.

The study investigated the main risks associated with food about which the Taekwondo college students were concerned (See the Table 2). The risk associated with food in the FNSE group, is the presence of toxic chemicals, and the second is food poisoning; while the non-FNSE group's had an inverse choice. This choice might due to the FNSE group's knowledge of food poisoning and awareness of toxic chemicals as the source of food poisoning. The concerns of other risks associated with food in both groups were ranked in a similar order. Hygiene at the place, expired data and allergic reactions to Chinese Taekwondo college students are greater risks than obesity and digestion problem. Generally speaking, the difference in the concerns of risks associated with food was not significant across the two groups.

Among all students, doctors, food consumer groups and scientists are the top three trustable sources to be informed about the food risks (See the Tablet) while, government, media and food producers generate a comparatively low level of trust for both groups. The difference between two groups was observed to be insignificant, as the $p$ value of paired samples $T$ test was2.18 $(>0.05)$. However, the FNSE group showed more trust on the specialists of food and less trust on other information sources, compared to the non-FNSE group, when the mean score of individual information source for each group was examined. In sum, the FNSE group and nonFNSE group showed similar attitudes toward food nutrition and safety and only demonstrated slight differences on several questions. Hence, food nutrition and safety education did not affect Chinese college taekwondo students' attitudes towards food nutrition and safety. The Chinese Taekwondo college students emphasized on food quality, showing great concern about food poisoning and toxic chemicals, and therefore trusted food specialists . Basically, the Chinese college taekwondo students had positive attitudes toward food nutrition and safety, and desired to have health and quality-guaranteed food.

However, two groups of students showed several differences regarding their dietary behaviors.

First, the non-FNSE group did not have clear understanding of health diet, and was not able to accurately self-assess their own dietary behaviors, while the FNSE group did better. In the FNSE group, 3.2\% and 26.4\% students considered that they did excellent or very well on health diets and the percentages for the non-FNSE group were $6.5 \%$ and $35.0 \%$. The students of the nonFNSE group demonstrated higher self-assessment. However, as the analysis of students' dietary behaviors revealed, $33.3 \%$ of students in the non-FNSE group with high self-evaluation of their health dietary behaviors used to consume extra sweet or salted food daily/frequently; and $9.8 \%$ of them used to have barbecue or spicy hotpot daily/frequently. Among the students with high selfevaluation in the FNSE group, only $18.9 \%$ and $0.8 \%$ of them had the habit of consuming over sweet/ salted food or barbecue or spicy hotpot daily/frequently.

Secondly, the FNSE group demonstrated strict selfrequirement regarding health diet, and clear awareness of own unhealthy dietary behavior. $12.8 \%$ of the students in the FNSE group stated they had unsatisfactory dietary behaviors, and $43.75 \%$ of them frequently consumed extra sweet or salted food. In the non-FNSE group, only $11.3 \%$ of students considered that they had unsatisfactory dietary behaviors, while $78.6 \%$ of them frequently consumed extra sweet or salted food. Third, the Chinese college taekwondo students, generally showed great demand of food nutrition and safety knowledge and willingness of implementations of health dietary behaviors. Specifically, more than $90 \%$ of students with lower self-evaluation of the health dietary behavior in the FNSE group were willing to improve their dietary behaviors and gain more nutrition and safety knowledge. In the non-FNSE group, the percentage of students who were willing to do so was around $78 \%$.

\section{CONCLUSION}

The results of this study indicate that Chinese Taekwondo college students have some basic knowledge of food nutrition and safety. Compared with the results of studies conducted several years ago, this study shows that Taekwondo college students' knowledge of food nutrition and safety has been improved.

The improvement in Taekwondo college students' knowledge of food nutrition and safety owes credit to the disclosures of food safety issues, the increase of health dietary notion, and the multiple information sources of food safety and nutrition. The students who had food nutrition and safety education attained more specialized knowledge, which confirmed the result of pervious research. In summary, the food nutrition and safety education have positive influence on obtaining food nutrition and safety knowledge.

Regarding the attitudes of food nutrition and safety, two groups did not show any differences. All of them emphasized on the quality, health and freshness of food. Their most concerned risks of food were food poisoning and toxic chemicals and most reliable information sources were doctors, food consumer groups and scientists. In this study, Taekwondo college students inclined to gain food nutrition and safety information from specialists, while the preferred information sources of Taekwondo college students were media and public speech, according to a pervious study. The change reflected was that Taekwondo college students have become more prudent on food nutrition and safety issue.

In general, Taekwondo college students showed positive attitudes towards food nutrition and safety but attitudes did not necessarily lead to behaviors that increased the safety of the food consumed. With similar attitude, no matter either high or low self-evaluation, students in the FNSE group had healthier dietary practices than students in the other group. This result is contrary to the findings of previous studies which indicated that with food nutrition and safety 
knowledge, Taekwondo college students were not willing to implement health dietary practices.

In conclusion, the food nutrition and safety education facilities and Chinese taekwondo college students' food nutrition and safety knowledge, assist them to self-assess and improve their dietary practices. Through the food nutrition and safety education, the college taekwondo students pay more attention to strict requirements of healthy diets, and show strong desire of gaining food nutrition and safety knowledge. Due to the above positive influences, food nutrition and safety education should be provided to Chinese Taekwondo college students. The contents of the education should be tailored to meet the demands of students and besides the classroom teaching, means of education can also be diversified.

\section{CONFLICT OF INTEREST}

The author confirms that this article content has no conflict of interest.

\section{ACKNOWLEDGEMENTS}

This work was supported by the Key Project of Guangxi Social Sciences, China (No.gxsk201424), the Education Science fund of the Education Department of Guangxi, China (No.2014JGA268), and Guangxi Office for Education Sciences Planning, China (No.2013C108).

\section{REFERENCES}

[1] A.A. Jackson, "Human nutrition in medical practice: The training of doctors", The Proceedings of the Nutrition Society, vol. 60, pp. 257-263, 2001.

[2] K.M. Adams, K.C. Linden, M. Kohlmeier, and M.S.H. Zeisel, "Status of nutrition education in medical schools," The American Journal of Clinical Nutrition, vol. 83, pp. 941-944, 2006.

[3] L.E. Burke, and J. Fair, "Promoting prevention: skill sets and attributes of health care providers who deliver behavioral interventions," Journal of Cardiovascular Nursing, vol. 18, pp. 256-266, 2013.

[4] M.B. Potter, J.D. Vu, and M. C. Minihane, "Weight management: What patients want from their primary care physicians," The Journal of Family Practice, vol. 50, pp. 513-518, 2011.

[5] O. Sibel, "Food Safety Education Makes the Difference Food Safety Perceptions, Knowledge, Attitudes and Practices among Turkish University Students," Journal for Verbraucherschutz and Lebensmittelsicherheit, vol. 6, pp. 25-34, 2010.

[6] P. Howat, B. Maycock, L. Jackson, T. Lower, D. Cross, J Collins, and K. van Asselt, 2000, "Development of competency-based university health promotion courses," Promotion \& Education, vol. 7, pp. 33-38.

[7] Q. Yan, P. Gong, "Investigation on the Nutrition Knowledge Attitudes and Dietary Behaviors of University Students," Modern Preventive Medicine, vol. 3, pp. 520-524, 2008.

[8] G. Yang, P. Chen, Q. Wang, and W. Li, "Survey and Analysis of Nutritional Knowledge, Attitude, Practice of Nursing Students", Henan Journal of Preventive Medicine, vol. 3, pp. 166-168, 2006.

[9] Q. Zhang, S. Zeng, L. Zhu, and Z. Cai, "Nutritional Knowledge, Attitudes and Practices of Shantou University Students", Chinese Journal of School Health, vol. 5, pp. 412-413, 2001.

\footnotetext{
Received: June 10, 2015

Revised: July 29, 2015

Accepted: August 15, 2015

(C) Guo-qing Su; Licensee Bentham Open.

This is an open access article licensed under the terms of the (https://creativecommons.org/licenses/by/4.0/legalcode), which permits unrestricted, noncommercial use, distribution and reproduction in any medium, provided the work is properly cited.
} 